\title{
MULTIPLE SEX DETERMINING REGIONS IN A GROUP OF RELATED CHIRONOMUS SPECIES (DIPTERA:CHIRONOMIDAE)
}

\author{
JON MARTIN, CHALIOW KUVANGKADILOK, DIANNE H. PEART and BARRY T. O. LEE \\ Department of Genetics, University of Melbourne, Parkville Vic., 3052, Australia
}

Received 27.xi.79

\section{SUMMARY}

In a group of Australian Chironomus species, sex determining regions involved in male heterogamety have been found at a minimum of five different chromosomal locations. In one case, $C h$. oppositus $\mathrm{A}$, sex determining regions have been identified on two different chromosomes. It is uncertain whether this is a polymorphism or indicates the existence of multiple sex determining regions. It is argued that all the published data on sites of male determining regions are compatible with the five locations found in this study. On the basis of the postulated phylogeny of the studied group, the location of the sex determining regions would appear to have changed during speciation in all cases except one. The significance of these changes in location during the speciation process is discussed.

\section{Introduction}

Ghironomidae, in common with many other Diptera, do not in general have morphologically differentiated sex chromosomes. However, in the genus Chironomus, the sex linkage of certain inversions in Ch. tentans and Ch. pallidivittatus, as well as that of eye colour mutant in Ch. pallidivittatus, demonstrated that the males were the heterogametic sex (Beermann, 1955), the only exception being certain North American populations of $C h$. tentans in which female heterogamety is indicated (Thompson, 1971). It was not possible to determine whether sex determination was due to a balance system as in Drosophila (Bridges, 1925) or to a dominant male determiner as in Lucilia (Ullerich, 1963).

The general location of sex determining regions has been established in a number of other species (table 5). These studies show that the sex determining region need not be in the same chromosome or chromosome arm (Beermann, 1955; Keyl, 1961; Rosin and Fischer, 1972) and that for some species, for example, Ch. tentans (Beermann, 1955; Thompson, 1971) Ch. plumosus (Acton, 1957; Keyl, 1961; Rosin and Fischer, 1972) and Ch. nuditarsis (Rosin and Fischer, 1972) there may be more than one location for the sex determining region. Beerman (1955) interpreted his data on the basis that there was polymorphism for a Y chromosome.

In many Chironomus species, even though they may be highly polymorphic, there is no indication that sex linkage of inversions occurs in natural populations. In fact this would only be expected when the sex determining loci were actually included in the inverted region. If the sex determiners are linked to the inverted region and crossing-over can occur in the chromosome segment between them, the sex determining regions would be expected to be randomly distributed in natural populations unless selection or recent origin had lead to linkage disequilibrium (Geiringer 1944, 1948). Sex 
linkage of inversion sequences or of individual loci should however be seen among the offspring of individual crosses. While individual crosses are difficult to perform with most Chironomus species in the laboratory, egg masses from single females can be relatively easily collected and the offspring reared. If it is assumed that the egg mass represents the result of a single mating, the offspring may be analysed to look for evidence of sex linkage in segregating inversions. Rosin and Fischer (1972) used this approach to locate sex determining regions in several European species. They point out that not all egg masses will provide useful information. Even if there are inversions segregating, only those crosses in which the male parent was heterozygous will be meaningful and the heterozygosity must be inferred from the distribution of inversions in the offspring when the parental karyotype is unknown. Despite these limitations, this technique is currently the only means of investigating sex determination in many species.

While European populations of $C h$. tentans and Ch. pallidivittatus share a common sex determining region, although with differences in the complexity of the inversions involved (Beermann, 1955), a group of related Australian species, Ch. oppositus, Ch. australis and Ch. duplex, have the sex determining loci in different chromosomes (Martin, quoted in White, 1978). This is a common feature of many Simuliidae where it appears that the sex determining region is replaced during speciation (Rothfels, 1979; Bedo, 1975; White, 1978). The extent to which such replacement occurs in Chironomus species remains to be determined.

In this paper we report in more detail the sex determining regions of the three forms of Ch. oppositus, Forms A, B and C (Martin et al., 1978) and three members of the Ch. australis group, Ch. australis, Ch. duplex, and Ch. occidentalis (Martin, 1971). This group of six taxa is relatively well defined cytologically although the specific status of the forms of $C h$. oppositus has not yet been settled. Form B is relatively distinct from Forms A and C which can only be accurately separated on the basis of whether or not the inversion sequences in arm A show sex linkage in natural populations (Martin and Lee, 1980). In earlier studies only two species were recognised in the $C h$. australis group (Martin, 1971). Subsequently material from Western Australia has been recognised as representing a distinct species with only three polytene chromosomes, as in Ch. duplex, but having a number of inversion differences (Martin, unpubl.) as well as differing in the number of nucleoli (Lentzios and Stocker, 1979). The Western Australian material has been called $C h$. occidentalis and is considered to be a distinct species even though it will hybridise with $C h$. duplex under laboratory conditions. The hybrids are fertile and can be used to investigate sex determination in these two species. Since the chromosomes of the hybrid are recognisable as to the species of origin, their presence in backcross progeny and in some cases whether the chromosome has undergone an exchange can be determined. It is of particular importance to be able to follow the $\mathrm{Y}$ chromosome of the original male parent. This technique can also be used with hybrids between some of the forms of $C h$. oppositus although to a limited extent because of the difficulty in recognising the parental chromosomes in some hybrids (Martin and Lee, 1980).

Therefore, by a combination of techniques, we have been able to compare the location of sex determining regions in all members of this group and assess the importance of replacement of such regions in speciations. 


\section{Materials AND Methods}

Most of the material used in this study has been either bred in the laboratory or obtained from wild collected egg masses subsequently reared in the laboratory. This necessitated the development of a culturing technique suitable for the Australian species. A variant of the medium developed for European species by Walter (1973) has been used, with the proportions of various ions adjusted to the high $\mathrm{Na}^{++}$and $\mathrm{Cl}^{-}$levels normally found in Australian waters (Bayly and Williams, 1973). Each salt was made up as a separate concentrate, $100 \mathrm{ml}$ of concentrate containing: $1.0 \mathrm{~g} \mathrm{NaHCO}_{3}, 5.0 \mathrm{~g} \mathrm{NaCl}, 1.0 \mathrm{~g} \mathrm{CaCl}_{2}, 0.2 \mathrm{~g} \mathrm{KH}_{2} \mathrm{PO}_{4}, 1.0 \mathrm{~g} \mathrm{MgSO}_{4}$ and $1.8 \mathrm{~g} \mathrm{MgCl}_{2}$ respectively. The basic medium was obtained by adding $1 \mathrm{ml} / 1$ of each concentrate. This solution called 1X Martins, has Total Dissolved Solids (TDS) of $75 \mathrm{ppm}$. Solutions of higher TDS can be made by increasing the quantity of each concentrate to give $2 \mathrm{X}, 3 \mathrm{X}$, etc. The medium was supplemented with either $\mathrm{FeCl}_{3}$ or $\mathrm{FeSO}_{4}$, made up as a 0.1 per cent solution and added at the rate of $0.2 \mathrm{ml} / 1$ regardless of the concentration of other salts.

Egg masses were set up in individual containers, with a bottom area of about $625 \mathrm{~cm}^{2}$, in 41 of solution. Three Kleenex industrial wipers, washed in absolute ethanol, were shredded and added to provide a substrate on which the larvae could build their tubes and feed. Additional tissues were added as necessary. Further food was provided in the form of Trout Starter 1C (supplied by Rural Chemical Industries) at the rate of $0.2 \mathrm{~g}$ initially and $0.4 \mathrm{~g} /$ week. This was supplemented by $1 \mathrm{ml}$ of a solution containing $0.6 \mathrm{~g}$ Thiamine $\mathrm{HCl} / 100 \mathrm{ml}$, given at the time of setting up the egg mass. Containers were aerated continuously with filtered air.

Egg masses or larvae of Chironomus oppositus were reared in 1X Martins; Ch. australis, Ch. occidentalis and Ch. duplex-Ch. occidentalis hybrids or backcrosses in 2X Martins; Ch. duplex in 3X or 4X Martins. Larvae for cytological analysis were removed at late fourth instar and sexed by examination of the ventral invaginations of the twelfth segment (Martin, 1962). Whenever possible the sexing was double checked to eliminate errors. Egg masses of the various forms of $C h$. oppositus have come from a number of areas, particularly Bellerive and Queenstown, Tasmania; Anglesea, Mitcham and Albert Park in Victoria. Ch. duplex material has come from the Metropolitan Farm, Werribee, with some samples from Lake Learmonth near Ballarat, both in Victoria. Ch. australis egg masses were from several localities in Tasmania, Kimba, South Australia and Belconnen, A.C.T. The exact source of the Ch. occidentalis egg masses is not known but is probably in the vicinity of Perth, W.A.

Laboratory matings were carried out in cages $0.3 \mathrm{~m}^{3}$ in a controlled temperature room $\left(20^{\circ} \mathrm{C}\right)$ with a $16 \mathrm{hr}$ light $/ 8 \mathrm{hr}$ dark cycle, including $1 \mathrm{hr}$ artificial twilight at dawn and dusk. For Ch. oppositus crosses, at least 20 males were required (Martin and Lee, 1980), while for Ch. duplex, Ch. occidentalis or their hybrids only a few males were needed. Ch. australis has not been bred successfully in the laboratory. Egg masses were collected, checked for fertility and then reared in the same manner as wild collected masses.

The same basic protocol applied when using hybridisation to observe sex determining regions regardless of the species involved. This protocol 


\section{PARENTAL SPECIES}

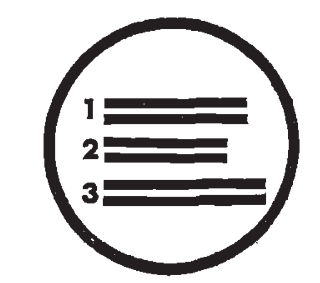

CH. OCCIDENTALIS ó

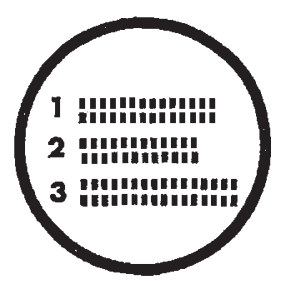

CH. DUPLEX 9

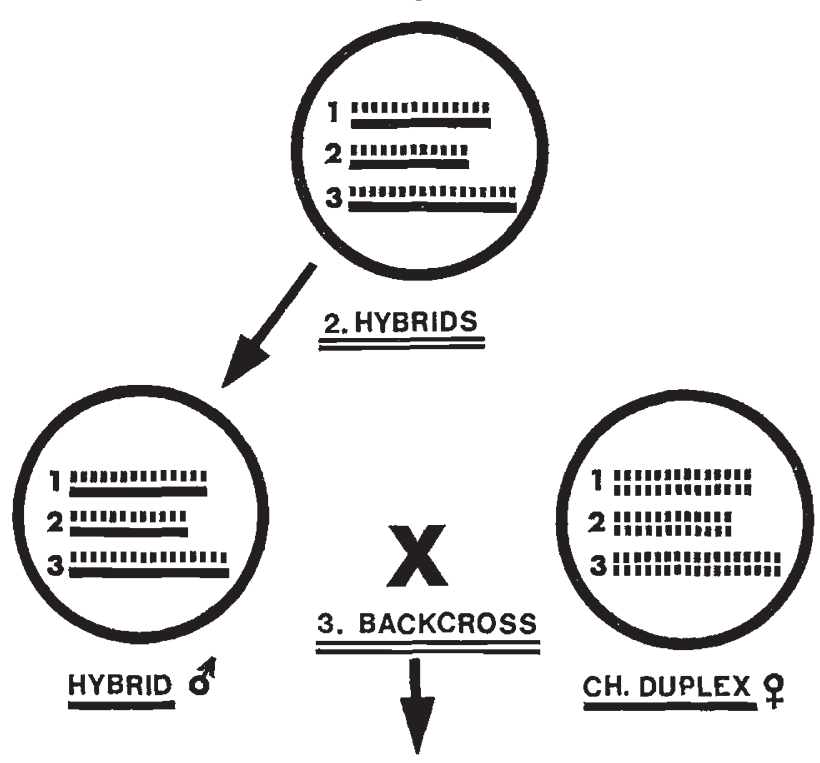

THE POSSIBLE CROMOSOME COMBINATIONS IN THE BACKCROSS PROGENY.
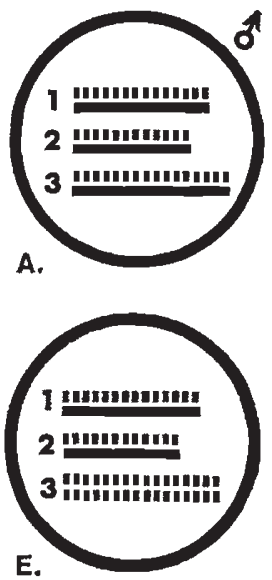
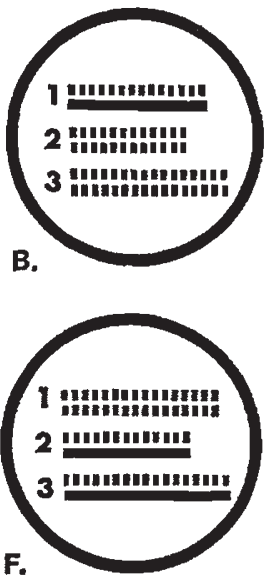
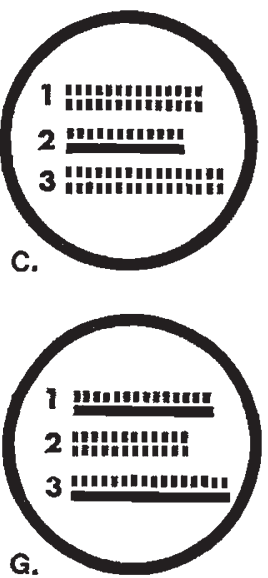
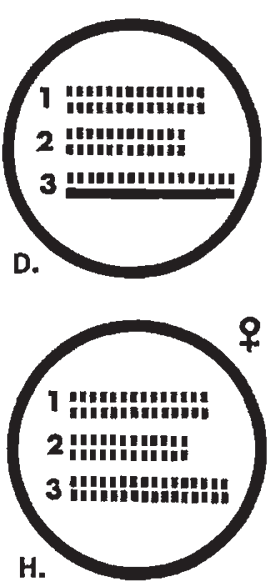

FIG. 1.-Schematic outline of the crosses involved in using hybridisation between Chironomus occidentalis and Ch. duplex to identify the $\mathrm{Y}$ chromosome of Ch. occidentalis. 3 -karyotype which will definitely be male. O-karyotype which will definitely be female. The sex of the other backcross karyotypes can only be determined by the analysis of the results of such crosses. 
for Ch. occidentalis is shown in fig. 1. A male of the species under study (Ch. occidentalis) was mated to a female of another species or form (Ch. duplex). The hybrid male must therefore carry the male sex determining region of the original $C h$. occidentalis male and this chromosome will pass only to male offspring in a backcross. The hybrid male may be backcrossed to females of either parent form but for simplicity of scoring the form of the original female parent was normally used (Ch. duplex). The only $C h$. occidentalis chromosomes in the cross then are from the hybrid male, and the backcross larvae may be easily scored to determine which chromosome arm passes always to male offspring. In the case of backcrosses using the forms of Ch. oppositus, some arms cannot be scored since both parents may carry the same sequence.

\section{RESULTS}

The analyses of egg masses, whether wild caught or laid in the laboratory, are consistent with the assumption that even though the parents are unknown, they are the result of single insemination. Each species will be considered separately, the inversion terminology follows previous usage for Chironomus oppositus (Martin et al., 1978) and Ch. duplex (Martin, 1971).

Chironomus oppositus Form A (Ch. oppositus $A$ )

This form is highly polymorphic with inversions in all chromosome arms, but there is no indication of sex linkage associated with any inversion in the natural populations studied so far (Martin, 1969; Martin et al., 1978). Egg masses have been investigated in which an inversion was segregating in $\operatorname{arm} \mathrm{B}, \mathrm{F}, \mathrm{D}, \mathrm{C}$ or $\mathrm{A}$ as the result of a homozygote $\times$ heterozygote mating. Inversions in arms F, D and $\mathrm{C}$ have shown evidence of sex linkage (table 1 ).

TABLE 1

Segregation of inversion sequences in arms $F, D$ and $C$ of $\mathrm{Ch}$. oppositus Form $A$

$\begin{array}{llccc}\text { Egg Mass } & & \mathrm{F}_{2} / \mathrm{F}_{1} & \mathrm{~F}_{1} / \mathrm{F}_{3} & \text { Total } \\ \text { Anglesea, Vic. } & & & & \\ \text { Egg mass 210 } & \text { Female } & 27 & - & 27 \\ \text { Egg mass 218 } & \text { Male } & - & 33 & 33 \\ & \text { Female } & 28 & - & 28 \\ \text { Male } & - & 28 & 28 \\ \text { Albert Park, Vic. } & & \mathrm{D}_{1} / \mathrm{D}_{1} & \mathrm{D}_{1} / \mathrm{D}_{4} & \text { Total } \\ \text { Egg mass 3 } & \text { Female } & - & 26 & 26 \\ & \text { Male } & 20 & - & 20 \\ \text { Mitcham, Vic. } & & \mathrm{D}_{1} / \mathrm{D}_{1} & \mathrm{D}_{1} / \mathrm{D}_{3} & \text { Total } \\ \text { Egg mass 2 } & \text { Female } & 67 & 1 & 68 \\ \text { Egg mass 7 } & \text { Male } & 1 & 59 & 60 \\ & \text { Female } & 51 & 67 & 118 \\ \text { Melbourne Exhibition } & & 48 & 36 & 84 \\ \text { Gardens, Vic. } & & & & \\ \text { Egg mass 4 } & \text { Female } & \mathrm{C}_{2} / \mathrm{C}_{2} & \mathrm{C}_{1} / \mathrm{C}_{2} & \text { Total } \\ & \text { Male } & - & 1 & 26 \\ \text { Queenstown, Tas. } & & \mathrm{C}_{1} / \mathrm{C}_{1} & \mathrm{C}_{1} / \mathrm{C}_{2} & 26 \\ \text { Egg mass 2 } & \text { Female } & 12 & 9 & \text { Total } \\ & \text { Male } & 5 & 1 & 6\end{array}$


Sequence $F_{3}$ is rarely found and only two egg masses segregating this sequence along with $\mathrm{F}_{\mathbf{1}}$ have been scored. In both, $\mathrm{F}_{\mathbf{3}}$ was segregated into the male larvae only.

Inversions in arms $\mathrm{D}$ and $\mathrm{C}$ are considered together because the results are basically similar. The inversions in these arms do not always show sex linkage (e.g., Martin and Lee, 1980 and table 1). This is to be expected because only those egg masses in which the male parent was heterozygous would show evidence of sex linkage (Rosin and Fischer, 1972). Therefore egg masses showing no evidence of sex linkage would result from crosses where the female parent was heterozygous.

Among those egg masses which showed sex linkage, some produced virtually all heterozygous male and homozygous female larvae. In other cases the females were heterozygous and the males homozygous. The heterozygous male parent will carry one sequence in common with the homozygous female parent and a different sequence on the homologue. If the different sequence is on the $\mathrm{Y}$ chromosome the male offspring will be heterozygous, but if it is on the paternal $\mathrm{X}$-chromosome then the female offspring will be heterozygous. The two arm $D$ inversions scored, $D_{3}$ and $\mathrm{D}_{4}$, are about the same length so the results for the two egg masses involving these inversions were pooled and showed a recombination frequency of $1 \cdot 2$ per cent between the inversion and the sex determining loci. The small sample involving arm $\mathrm{C}$ showed a recombination frequency of about 2 per cent. The fact that inversions on either the $\mathrm{D}$ or $\mathrm{C}$ arm may show linkage and small amounts of recombination with the sex determining loci is best explained by assuming that this sex determining region is near the centromere of the DG chromosome. Therefore there would appear to be at least two sex determining regions in this form, one in $\operatorname{arm~} \mathrm{F}$ and the other near the CD centromere.

\section{Ch. oppositus Form $B$ (Ch. oppositus $B$ )}

There is no indication of sex linkage associated with an inversion sequence in natural populations of this form. Egg masses have been investigated in which inversions in arms B, F, G, A or G were segregating. Only an inversion in arm $G$ showed evidence of sex linkage in some cases (table 2; Martin and Lee, 1980). Although arm G is relatively short, there is recombination between the small inversion and the sex determining region. The results (table 2) suggest that there is heterogeneity in the recombination frequency between different egg masses. The three generations derived from egg mass 26 show no significant heterogeneity but the frequency from all egg masses varied from less than 1 per cent to over 9 per cent of recombination. The egg mass with the highest frequency of recombination had three other inversions segregating while the egg mass with the lowest frequency had two other inversions, compared to the intermediate egg mass 26 series with only one other inversion segregating. This would suggest that recombination frequency is influenced by the genetic background, and may also depend on the proportion of the genome tied up in inversion heterozygosity, but these results would imply no direct correlation.

\section{Ch. oppositus Form $C$ (Ch. oppositus $C$ )}

Form $\mathrm{C}$ has been defined cytologically on the basis that arm $\mathrm{A}$ inversions show sex linkage in natural populations. This sex linkage has been con- 
TABLE 2

Segregation of arm $G$ sequences showing sex linkage in Ch. oppositus Form B from Bellerive, Tasmania

\begin{tabular}{|c|c|c|c|c|}
\hline Egg mass & & $\mathrm{G}_{\mathbf{1}} / \mathrm{G}_{1}$ & $\mathrm{G}_{1} / \mathrm{G}_{2}$ & Total \\
\hline \multirow[t]{3}{*}{9} & Female & 77 & 1 & 78 \\
\hline & Male & & 51 & 51 \\
\hline & \multicolumn{4}{|c|}{ Recombination between inversion and sex region $=0.8 \%$} \\
\hline \multirow[t]{3}{*}{10} & Female & 94 & 7 & 101 \\
\hline & Male & 8 & 55 & 63 \\
\hline & \multicolumn{4}{|c|}{ Recombination between inversion and sex region $=9 \cdot 2 \%$} \\
\hline \multirow[t]{3}{*}{26} & Female & 22 & 2 & 24 \\
\hline & Male & 1 & 25 & 26 \\
\hline & \multicolumn{4}{|c|}{ Recombination between inversion and sex region $=6.0 \%$} \\
\hline \multirow{3}{*}{$F_{1}$ of 26} & Female & 15 & 1 & 16 \\
\hline & Male & - & 22 & 22 \\
\hline & \multicolumn{4}{|c|}{ Recombination between inversion and sex region $=2 \cdot 6 \%$} \\
\hline \multirow[t]{2}{*}{$F_{2}$ of 26} & Female & 12 & - & 12 \\
\hline & Male & 1 & 11 & 12 \\
\hline & \multicolumn{4}{|c|}{$\begin{array}{l}\text { Recombination between inversion and sex region }=4.2 \% \\
\text { Recombination between inversion and sex region (all } \\
\text { generations of egg mass } 26)=4.5 \% \\
\text { ogeneity of recombination rates all egg masses. } \\
\chi_{2}^{2}=8.51 \quad P<0.02\end{array}$} \\
\hline
\end{tabular}

firmed from the segregation patterns in a number of egg masses and laboratory crosses of Form $\mathrm{G}$ males to Form B females. In most of the egg masses studied there was no recombination between the inversion and the sex determining region. From a total of 1080 larvae examined only four individuals, from three egg masses out of 55 , showed recombination, a frequency of 0.37 per cent. However, since these egg masses were not double-checked for the sex of the larvae, it is possible that the small apparent recombination frequency simply reflects the frequency of misclassification and that the sex determination is completely linked with the inversions $A_{2}$ and $A_{3}$ which both cover much the same region (Martin, 1969; Cragg, unpubl.).

In addition to the arm $A$ sequences, the segregation of inversions in arms $\mathrm{B}, \mathrm{D}, \mathrm{G}$ or $\mathrm{E}$ was investigated. Arm $\mathrm{E}$ shows evidence of sex linkage in some backcrosses of hybrid males, resulting from the cross of Form $\mathrm{C}$ males with Form B females, to females of either Form B or Form C. This is presumably linkage to the sex determining region in arm $A$, the other arm of chromosome III (Martin, 1969). In hybrids derived from Anglesea, Vic., recombination frequency between the sex determining region and inversion $\mathrm{E}_{2}$ is about 30 per cent, while in hybrids derived from Bellerive, Tas., there is independent assortment of arm $\mathrm{E}$ sequence and sex.

One small egg mass sample, however, suggested sex-linkage of arm D sequence since, of the 12 females scored, nine were $D_{1} / D_{2}$ and three $D_{2} / D_{2}$, whereas in the 12 males, eight were $D_{1} / D_{1}$ and four $D_{1} / D_{2}$. This egg mass would appear to have resulted from a cross between two heterozygotes in which the male or even the female chromosomes were acting as a heterogametic pair. However, this result is probably due to chance since the egg mass was obtained from a laboratory cross of adults from two other egg masses which show no evidence of sex linkage in arm D. Also there is no 
evidence of sex linkage of this arm in hybridisation crosses in which it is known that the male parent was heterozygous for $D_{1} / D_{2}$.

Ch. australis

Although no inversions are known in this species, there is definite indication in natural populations that there is a sex determining region near the centromere of the CD chromosome. The presence of three heterochromatic bands near the centromere of the CD chromosome which are heterozygous in males but homozygous in females suggests that there is a sex determining region in this area. The sex linkage of these bands has been confirmed in egg mass material.

\section{Ch. duplex}

Some natural populations of this species show clear sex linkage of the Werribee (We) inversion in arm B (Martin, 1967, 1971). The examination of egg mass material has clearly confirmed the presence of a sex determiner in $\operatorname{arm} \mathrm{B}$, even in those populations which are homozygous for the Werribee sequence. Linkage between the inversion and the sex determining region is very tight with only a single confirmed recombinant being recorded, a crossover frequency of 0.3 per cent. Analysis of larvae from the backcross of male hybrids, from the cross between $C h$. duplex males $\times C h$. occidentalis females, to $C h$. duplex also confirmed the presence of the Ch. duplex sex determining region on chromosome $\mathrm{l}(\mathrm{BF})$. All male offspring carried the duplex chromosome 1, as shown by the results of a typical backcross (table 3), or at least carried part of the duplex arm B if recombination had occurred. So far, 9 recombinants have been found amongst 167 backcross larvae examined.

There are two regions paired in arm $B$ of the hybrids; region 1 from about $1 \mathrm{~B} 2$ to $1 \mathrm{D} 5$ and region 2 from about $3 \mathrm{Al}$ to $1 \mathrm{D} 3$ (fig. 2). On the basis of the We sequence (Martin, 1971), it is possible to recognise recombination in the region $1 \mathrm{Al}$ to about $1 \mathrm{~B} 2$; from about $1 \mathrm{D} 6$ to $3 \mathrm{Al}$ and from about $3 \mathrm{Bl}$ to the centromere if crossing over has occurred in either of the two

TABLE 3

Segregation of Chironomus duplex chromosomes in the offspring of a backcross involving a hybrid male from the cross $\mathrm{Ch}$. duplex $\delta \times \mathrm{Ch}$. occidentalis 우 (DOO backcross No. 1 )

Chromosomes of Ch. duplex origin

Chrom 1, 2 \& 3

Chrom 1 \& 2

Chrom 1 \& 3

Chrom 2 \& 3

Chrom 1 only

Chrom 2 only

Chrom 3 only

None (i.e., all Ch. occidentalis)

Total

\begin{tabular}{cc}
\multicolumn{3}{c}{ Sex of offspring } \\
5 & + \\
16 & 0 \\
6 & 0 \\
$8^{*}$ & 0 \\
0 & 9 \\
11 & 0 \\
0 & 5 \\
0 & 11 \\
0 & 11 \\
41 & 36
\end{tabular}

* Includes one individual with recombination in chromosome 1 (see text). 


\section{Plate I}

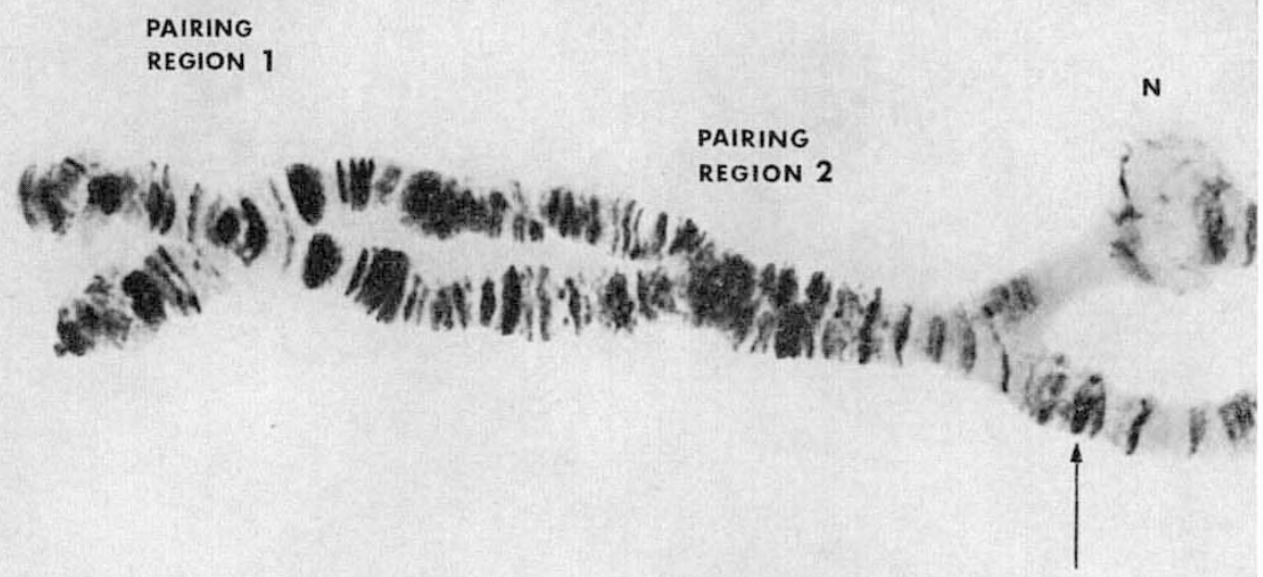

FIG. 2.-Arm B of a hybrid between Chironomus duplex and Ch. occidentalis showing the two regions of pairing when the $C h$. duplex sequence is We. N-nucleolus of the Ch. duplex (We) sequence. Arrow indicates the centromere of the Ch. occidentalis homologue.

FIG. 3.-Arm E (left) and arm A (right) of a hybrid between Chironomus duplex and Ch. occidentalis. The Ch. duplex homologue carries the Oat sequence in $\operatorname{arm} \mathrm{A}$ and the two regions of pairing with the Ch. occidentalis homologue are indicated. N-nucleulus of the $C h$. duplex homologue. Arrows indicate the centromeres of the two homologues. 
pairing regions. Three males were recombinant as a result of a crossover in pairing region 2, so that all the chromosome proximal to 1 D3 was occidentalis, the distal region, at least up to $3 \mathrm{Al}$, being duplex. Two other males were the result of a crossover in pairing region 1. These males carried the occidentalis sequence to at least $1 \mathrm{~B} 2$ and the duplex sequence from at least $1 \mathrm{D} 5$ to the end of arm F. Two females resulted from recombination in region 1, with the duplex sequence at least to $1 \mathrm{~B} 2$ and then occidentalis from at least $1 \mathrm{D} 5$ to the end of arm F. Another female resulted from recombination in region 2, with the occidentalis sequence at least to $3 \mathrm{Al}$ and the duplex sequence proximal to pairing region 2 . Thus all males carried the region $1 \mathrm{D} 6$ to $3 \mathrm{Al}$ plus all or at least part of pairing regions 1 and 2 of the duplex We sequence, while the females lacked this region. The sex determining region should therefore lie between the limits 1 D6 to $3 \mathrm{Al}$ of the We sequence. The occurrence of crossing over between the Werribee inversion and the sex determiners would suggest it is not actually in the region of the inversion, about $2 \mathrm{~A} 1-2 \mathrm{D} 2$, although the possibility that the recombination is the result of a rare double crossover cannot be excluded. It is possible that the sex determiners are in one or other of the other two pairing regions, but if this is the case recombinants of the "wrong " sex should be recovered when larger samples are analysed.

Arm $\mathrm{F}$ also shows some evidence of sex linkage in egg mass data, although there is no indication of this in the frequency of the Farm inversion in natural populations. It was not always known whether the male or the female parent was heterozygous in the egg mass data, nor was it always able to be deduced from the results due to the relatively high level of recombination between the inversion and the sex determining region. By pooling the data of those few crosses in which the male was known to be heterozygous plus any which showed a significant or at least a consistent (e.g., deficiency of $\mathrm{St}^{\mathrm{Fa}}$ female and $\mathrm{Fa}$ male) deviation from random assortment, a minimum estimate of 34 per cent recombination between the inversion on arm $F$ and the sex determining region on arm B was obtained. Although some of these crosses constituted a three-point test cross, i.e., heterogametic males heterozygous for both the Werribee and Farm inversions, no recombinants between the Werribee inversion and the sex determining region were recovered so there was no indication on which side of the Werribee inversion the sex determiners were located. Backcrosses of the hybrid males indicate strong sex linkage of arm $F$ because the limited pairing results in a low frequency of recombination between the sex determining region and arm $F$ (fig. 2). Neither the Metropolitan inversion on arm D, nor the Oatland inversion on arm A (Martin, 1971), show any indication of sex linkage in egg mass data. Chromosome II and III segregate randomly in hybrid backcrosses.

\section{Ch. occidentalis}

Only small samples from natural populations have been examined and few inversion heterozygotes were observed. The egg masses from which the laboratory stocks were derived showed no inversion polymorphism. The only data on the location of sex determining regions of this species therefore comes from backcrosses of hybrids derived from a Ch. occidentalis male. Typical results of such backcrosses are shown in table 4. Chromosome III (arms GEA) passes to males except in some recombinants. The other 
chromosomes segregate equally to each sex. So far, a total of 11 recombinants for chromosome III have been observed amongst 136 backcross larvae. Pairing of the homologues in the hybrid male will be slightly different, depending on whether the duplex sequence is Standard ( $\mathrm{St}^{\mathrm{O} a t}$ ) or Oatlands (Oat). In the polytene chromosomes of the hybrid there are two pairing regions. Region 1 is from about $14 \mathrm{~B}$ to the middle of $14 \mathrm{D}$, the limits at both ends being set by physical changes, a nucleolus in $14 \mathrm{~A}$ and an inversion of the region distal to 14 D8. Study of the recombinants, however, indicates

\section{TABLE 4}

Segregation of Chironomus occidentalis chromosomes in the offspring of a backcross involving a hybrid male from the cross $\mathrm{Ch}$. occidentalis o $\times \mathrm{Ch}$. duplex 우 $(O D D$ backcross No. 1)

$\begin{array}{lcc}\text { Chromosomes of } & \text { Sex of offspring } \\ \text { Ch. occidentalis origin } & 0 & + \\ \text { Chrom 1, } 2 \text { \& } 3 & 9 * & 0 \\ \text { Chrom 1 \& } 2 & 0 & 4 \\ \text { Chrom 1 \& } 3 & 7 & 0 \\ \text { Chrom 2 \& 3 } & 3 & 1 * \\ \text { Chrom 1 only } & 0 & 11 \\ \text { Chrom 2 only } & 0 & 4 \\ \text { Chrom 3 only } & 8 & 0 \\ \text { None (i.e., all Ch. duplex) } & 0 & 8 \\ \text { Total } & 27 & 28 \\ \text { * includes 1 } \sigma^{*} \text { and 19 showing recombination in } \\ \text { chromosome 3. }\end{array}$

that the nucleolus is not a physical block to pairing in meiosis since crossovers occur up to region 13D. Region 1 is in the same relative position in both StOat and Oat. Region 2 is from about $15 \mathrm{Cl}$ to $15 \mathrm{E} 7$. In the case of StOat this segment is at the end of the chromosome while in Oat the region $15 \mathrm{~B} 9$ to $15 \mathrm{El}$ is inserted between $15 \mathrm{E} 6$ and 7 (Martin, 1971), so that pairing region 2 is about 18-20 bands from the end (figure 3). Recombination in region 2 was not relevant, so the results are independent of which duplex sequence was involved.

There were five males recombinant in chromosome III. All of these carried the occidentalis sequence for arms $\mathrm{G}$ and $\mathrm{E}$ and region 14A, a crossover having occurred somewhere in the $14 \mathrm{~B}-14 \mathrm{D}$ region, so that the distal part of the arm carried the duplex sequence. Recombinant females were of two types. Two of them carried the occidentalis sequence of arm $\mathrm{G}$ and up to region $13 \mathrm{D}$ of arm $\mathrm{E}$ and then the duplex sequence with the nucleolar organiser and arm A. The other four females were the reciprocal of the male recombinants, i.e., duplex sequence from arm $\mathrm{G}$ to $14 \mathrm{~B}-\mathrm{D}$, and then the distal end of arm A with the occidentalis sequence. These results would indicate that the sex determining region is near the centromere, in region $14 \mathrm{~A}$ of $\operatorname{arm} \mathrm{A}$.

\section{Discussion}

The results indicate that a minimum of five sex determining regions are present in this group of Chironomus taxa. Since these sex determining regions do occur at different locations it is of interest to assess the role of these changes in the speciation process. 
In the case of Chironomus oppositus the specific status of the three forms has not yet been decided, although Form B is clearly distinguishable from Forms A and C (Martin and Lee, 1980). The present work indicates that the three forms differ in the location of the sex determining genes. This does not necessarily mean that they are distinct species, nor do our results preclude the possibility of other sex determining regions in these taxa. Two basic problems prevent the use of sex determining regions as a criterion for species differentiation in this group. First, there are two different sex determining regions amongst material considered to be Form $\mathrm{A}$, one on Chromosome I and the other on Chromosome II. Secondly, the limitations of the techniques available have prevented us from determining how widespread the different regions are in distribution and whether they are ever present in the same individual. In other species, such as Ch. tentans (Beermann, 1955) and Ch. nuditarsis (Rosin and Fischer, 1972), the presence of two sex determiners in the same population has been demonstrated.

Beermann (1955) interpreted the presence of more than one sex determining region ( $Y$ determiner) in the same species as a polymorphism. There is, however, at least one other possible explanation, namely, that they are components of a complex sex determining system, operative in all males but not normally recognisable because of the rarity of visible markers in natural populations. When the previous reports of sex determining regions in the genus Chironomus are examined (table 5), it would appear that the minimum of five loci or regions would account for not only our results but all the published observations. These loci would be on arm $\mathrm{A}$ in the vicinity of the centromere (nuditarsis, crassicaudatus, plumosus, oppositus $\mathrm{G}$ and occidentalis) arm B near the telomere (tentans, pallidivittatus, and duplex); arm $\mathrm{G}$ near the centromere (east Canadian race of tentans, plumosus, australis and oppositus A); arm F possibly in region 16 of Keyl's (1962) map (tentans, annularius, obtusidens, rempelii, luridus, stigmaterus, bernensis and oppositus A); and on arm G (nuditarsis and oppositus $\mathrm{B}$ ).

The five sex determining regions can be derived from the data presented in table 5 if the following points are taken into account. In Ch. occidentalis the $\mathrm{Y}$ determiner is near the centromere, but in other species the location is not certain except that in Ch. nuditarsis it is near the centromere of the $\mathrm{AB}$ chromosome (Rosin and Fischer, 1972). To assume that the Ch. nuditarsis sex determiner is actually on arm $\mathrm{B}$ is inconsistent with the data from $C h$. tentans, Ch. pallidivittatus and $C h$. duplex where the sex determining regions are towards the telomere. Certainly the position of the sex determining regions will alter as the chromosomes are rearranged in speciation but the bands near the centromere regions are rarely affected (Keyl, 1962). Therefore it is more logical to assume that the Ch. nuditarsis sex determiner is actually in arm A, a similar location to that of Ch. occidentalis. The Y determiner in arm $\mathrm{B}$ would then represent a second region. In three of the species with a sex determining region on the CD chromosome, Ch. australis, Ch. plumosus, Ch. oppositus A (table 5), it has been found to be near the centromere. In Ch. australis the heterochromatic bands associated with the sex determining region are actually in arm $\mathrm{G}$ and in Canadian male heterogematic Ch. tentans a Y locus has been identified in arm C (Acton, 1959; Thompson and Bowen, 1972). It could therefore be argued that all these loci are on arm $\mathrm{C}$ near the centromere and that there is no sex determining region in arm $\mathrm{D}$.

The most commonly observed sex determining region is that in $\operatorname{arm} \mathrm{F}$, 
TAble 5

Listing of the position of the sex determining regions recorded in species of Chironomus and the means by which they were recognised

Chromo-

some

Arm

A

crassicaudatus

nuditarsis

occidentalis

oppositus C

plumosus

B

duplex

nuditarsis

pallidivittatus

tentans

(European)

C australis

oppositus A

plumosus

pallidivittatus

tentans

(European)

tentans

(Canadian)

D australis

oppositus A

plumosus

E none recorded

F luridus

annularius

bernensis

obtusidens

oppositus A

pallidivittatus

tentans

(European)

tentans (east

Canadian)

rempelii

stigmaterus

G nuditarsis

oppositus B
Location

outside inversion

near centromere

near centromere

outside inversion

outside inversion

distal to inversion

near centromere

at or near telomere

or near centromere

as for pallidivittatus

near centromere

near centromere

near centromere

in $\operatorname{arm} \mathrm{F}$

as pallidivittatus

outside inversion

near centromere

(in arm C?)

near centromere

near centromere

outside inversion

at or near telomere or segment 16 in the inversion

in the inversion?

in the inversion?

outside inversion?

at or near telomere or segment 16 in the

inversion

as pallidivittatus

우 determiner near

telomere

in the inversion?

in the inversion?

at distal end

outside inversion
Means of

recognition

complex inversion

complex and simple

inversions

species hybrid

simple inversion

complex inversion

complex inversion,

species hybrid

simple inversion

complex inversion

Author

15

11

16

8

1,5

6,16

11

3,11

complex inversion $\quad 3,11$

heterochromatic bands $\quad 16$

simple inversion $\quad 16$

simple inversion? 11

complex inversion 3

with arm $\mathrm{F}$

complex inversion

with $\operatorname{arm} \mathrm{F}$

complex and simple 2, 13

inversion

heterochromatic

bands

simple inversion

simple inversion?

16

11

simple inversion

1

complex inversion

3,5

simple inversion $\quad 11,14$

simple inversion with 4,5

heterochromatic

band

simple inversion

16

complex inversion

3

complex inversion

3

complex inversion

12,13

simple inversion

10

with puffed band

simple inversion with puffed band

simple inversion and

heterochromatic band

simple inversion

7,16

Key to list of authors: 1-Acton 1957, 2-Acton 1959, 3-Beermann 1955, 4-Keyl 1961, 5-Keyl 1962, 6-Martin 1971, 7-Martin \& Lee 1980, 8-Martin et al. 1978, 9-Martin \& Wülker 1974, 10-Rempel et al. 1962, 11-Rosin \& Fischer 1972, 12-Thompson 1971, 13-Thompson \& Bowen 1972, 14-Wülker \& Klötzli 1973, 15-Wülker \& Martin 1971, 16-present study. 
which Keyl (1962) suggests is in segment 16 of his map of this arm. Most of the cases listed in table 5 are compatible with this interpretation except Ch. stigmaterus, where the apparently closely sex linked inversion in segments 5-6a (Martin and Wülker, 1974) is some distance from segment 16. However, as there is no information on recombination in this species, the possibility of the $\mathrm{Y}$ determiner being in segment 16 cannot be ruled out. The presence of a sex linked inversion in Ch. luridus which splits segment 16 (Keyl, 1962) suggests that the proposed location of the sex determining region can be narrowed down to the bands $16 \mathrm{f}-\mathrm{g}$, which are included in the inversion. On the other hand, the female heterogametic sex determiner found in the eastern Canadian race of Ch. tentans (Thompson, 1971), which is on $\operatorname{arm} \mathrm{F}$, could not be located in segment 16 which is near the centre of the arm since Thompson and Bowen (1972) state that it is near the end of the arm. This female sex determiner may represent a sixth sex determining region.

Since $\operatorname{arm} \mathrm{G}$ is very much altered between species, there is no reason why the locus in $C h$. nuditarsis and Ch. oppositus B should appear to be in the same relative position in the arm. However, a distal location of the region in both species would be consistent with the existing data.

The significance of the five regions is not clear at present. It may be that only one region is functional in any individual or alternatively that all regions are functional. There are two lines of evidence from our results, which suggest that the latter is not correct. First, inversions in one species covering approximately the same region as those which show sex linkage in other species show no indication of sex linkage in any egg mass data. For example, inversion $\mathrm{B}_{2}$ of $C h$. oppositus shows no indication of sex linkage in any of the forms although it covers the region $2 \mathrm{Al}-2 \mathrm{D} 2$ in which the $C h$. duplex sex determiner was localised. Similarly, the arm A sequences of Ch. oppositus A and B, as well as Ch. duplex, do not show sex linkage, while those of $C h$. oppositus $\mathrm{C}$ do, yet the same sequences are present in Form $\mathrm{A}$ $\left(\mathrm{A}_{2}\right.$ and $\left.\mathrm{A}_{5}\right)$ and Form $\mathrm{B}\left(\mathrm{A}_{2}\right)$. Secondly, in backcrosses of $C h$. duplex $\times C h$. occidentalis and $C h$. oppositus $\mathrm{C} \times \mathrm{B}$ hybrids, only one chromosome from the original parent male segregated preferentially with regard to sex, the others segregated randomly. This evidence is not conclusive since crosses involving $C h$. oppositus $\mathrm{A}$, which is known to have sex determining regions in two different chromosomes, have not been successful. Such crosses would show definitely whether only one of the two sex determining regions is operative in any male. The results of the crosses so far made do not rule out the possibility that there are loci concerned with sex determination at all sites, but only one site is male determining.

In the group we have studied it is found that each of the five postulated sex-determining regions is the functional male determiner in at least one taxon. To understand the significance of this observation, some understanding of the phylogeny of the group is necessary. The phylogenetic relationships of some members of the group can be represented as follows (Martin, 1971; Martin and Lee, 1980):

Ch. oppositus $\mathrm{C}$

$$
\uparrow
$$

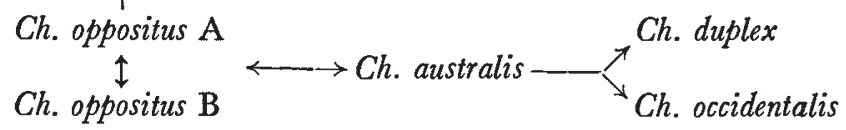


Based on this phylogeny we may assume that the CD sex determiner found in Ch. australis is the same as that in Ch. oppositus A, with the heterochromatinisation of the Ch. australis $\mathrm{X}$ chromosome occurring after speciation had occurred. With this exception, the other species all show a change in the location of the sex-determining region either during or following speciation. The phylogenetic distance between $C h$. oppositus $\mathrm{C}$ and $C h$. occidentalis makes it likely that the presence of a sex determining region in arm A of each taxon is the result of an independent event rather than derivation from a common ancestor. These changes in location between taxa can be compared to the situation in the Simuliidae which appear to have a similar sex determining mechanism. Vajime and Dunbar (1975) state that no two species of simuliid share an identical set of sex chromosomes. However, in many cases this refers to a sex determining region of similar location but identified by different inversions of heterochromatic bands (Bedo, 1975 ; 1979). Under this broad definition none of the Chironomus species studied would share the same sex determining mechanism, because although the sex determining regions may be in the same location they are associated with different inversions or cytological markers. These differences between species may be of similar significance in speciation to the differences between autosomal inversion polymorphisms but implies no change in the sex determining mechanism.

The presence of polymorphic sex determiners in Ch. oppositus A as well as in a number of other species suggests that changes in the sex determining region occur due to the fixation of the alternative regions in different daughter species. The fact that Ch. oppositus A is presently polymorphic for sex determiners would suggest that this species may be capable of further speciation, raising the question of whether the change in the location of sex determination regions in speciation is incidental or a cause of speciation. Beermann (1955) noted that in the presence of polymorphic $Y$ determiners the male population was split up in terms of sex determination since there was no way in which a $\mathrm{Y}$ determiner could transfer to a male carrying the alternative Y. Several authors have noted the tendency in both chironomids and simuliids, for the accumulation of inversions, or other mechanisms to reduce crossing over, in the vicinity of the sex determining regions (e.g., Beermann, 1955; Rothfels, 1956; Bedo, 1975, 1979). This could mean that a fairly large segment of the chromosome is tied to the sex determiner and hence incapable of transmission to males carrying an alternative $\mathrm{Y}$ chromosome. It may then be that the genes associated with the alternative $\mathrm{Y}$ chromosomes could adapt the males to different environments. One can then ask whether such a situation would ultimately be sufficient to subdivide the female population, perhaps aided by assortative mating or some other mechanism, to lead eventually to distinct species with different sex determining mechanisms. Computer simulation of this model is possible and may show whether this mode of speciation is theoretically feasible.

Acknowledgment.-This work was supported by Grants D71/17815, D1-77/15599 and D1-78/15465 from the Australian Research Grants Committee. We are grateful to the M.M.B.W. for permission to collect at the Metropolitan Farm, Werribee, to Dr D. H. D. Edward (University of Western Australia), Dr D. L. Porter and Mr G. Lentzios (both University of Melbourne) for provision of material and to Mss M. Sawyer, E. Harts and E. Marles for technical assistance. 


\section{REFERENCES}

AGron, A. B. 1957. Sex chromosome inversions in Chironomus. Am. Naturalist, 91, 57-59.

ACTON, A. B. 1959. A study of the differences between widely separated populations of Chironomus (Tendipes) tentans (Diptera). Proc. R. Soc. Lond., 151B, 277-296.

BAYLy, I. A. E., AND Williams, W. D. 1973. Inland Waters and their Ecology. Longman, Australia.

BEDo, D. G. 1975. Polytene chromosomes of three species of black-flies in the Simulium pictipes group (Diptera: Simuliidae). Canad. 7. Zool., 53, 1147-1164.

BEDO, D. G. 1979. Band and nucleolar polymorphisms in polytene chromosomes of Simulium ornatipes (Diptera: Simuliidae). Cytobios, 21, 113-133.

BeERMANN, w. 1955. Geschlechtsbestimmung und Evolution der genetischen Y-chromosomen bei Chironomus. Biol. Zbl., 74, 525-544.

BRIDGES, С. B. 1925. Sex in relation to chromosomes and genes. Am. Naturalist, 59, 127-137. GEIRINGER, H. 1944. On the probability theory of linkage in Mendelian heredity. Ann. Math. Stat., 15, 25-27.

GEIRINGER, H. 1948. On the mathematics of random mating in case of different recombination values for males and females. Genetics, 33, 548-564.

KeYL, H.-G. 1961. Chromosomenevolution bei Chironomus I. Strukturabwandlungen an speicheldrusen-chromosomen. Chromosoma, 12, 26-47.

KEYL, H.-G. 1962. Chromosomenevolution bei Chironomus II. Chromosomenumbauten und phylogenetische Beziehungen der Arten. Chromosoma, 13, 464-514.

LENTzios, G., AND sTocker, A. J. 1979. Nucleolar relationships in some Australian Chironomus species as shown by Ag-As banding and other cytological techniques. Chromosoma, $75,235-258$.

MARTIN, J. 1962. Interrelation of inversion systems in the midge Chironomus intertinctus (Diptera: Nematocera). I. A sex-linked inversion. Aust.F. Biol. Sci., 15, 666-673.

martin, J. 1967. Meiosis in inversion heterozygotes in Chironomidae. Canad. J. Genet. Cytol., 9, 255-268.

MARTIN, J. 1969. The salivary gland chromosomes of Chironomus oppositus Walker (Diptera: Nematocera). Aust. 7. Zool., 17, 473-486.

Martin, J. 1971. A review of the genus Chironomus (Diptera, Chironomidae). IV. The karyosystematics of the australis group in Australia. Chromosoma, 35, 418-430.

MARTIN, J., AND LEE, B. T. o. 1980. Problems in speciation of Chironomus oppositus in southeastern Australia. In Essays on Evolution and Speciation in Honor of $M . \mathcal{F} . D$. White, ed. W. R. Atchley and D. S. Woodruff. Cambridge University Press, London.

MARTIN, J., LEE, B. T. O., AND CONNOR, E. 1978. Apparent incipient speciation in the midge Chironomus oppositus Walker (Diptera: Chironomidae). Aust. F. Zool., 26, 323-329.

MARTIN, J., AND wülker, w. 1974. A review of the genus Chironomus (Diptera, Chironomidae). VIII. The cytology of Chironomus stigmaterus Say. Stud. Nat. Sci. (Portales, N. M.), 1, (11), 1-17.

MARTin, J., wÜlKER, w., AND sublette, J. E. 1974. Evolutionary cytology in the genus Chironomus Meigen. Stud. Nat. Sci. (Portales, N. M.), 1, (12), 1-12.

REMPEL, J. G., NAYLOR, J. M., Rothfels, K., AND otTonen, R. 1962. The sex chromosome constitution of Chironomid intersexes parasitised by Nematodes. Canad. F. Genet. Cyt., $4,92-96$.

Rosin, s., AND FISGHER, J. 1972. Polymorphismus des realisators für männliches Geschlecht bei Chironomus. Rev. Suisse Zool., 79, 119-141.

RотнFеLs, к. H. 1956. Black flies: siblings, sex and species grouping. f. Heredity, 47, 113-122.

Rothfels, K. H. 1979. Cytotaxonomy of black flies (Simuliidae). Ann. Rev. Entomol., 24, 5-7-539.

Thompson, P. E. 1971. Male and female heterogamety in populations of Chironomus tentans (Diptera: Chironomidae). Canad. Entomologist, 103, 369-372.

THOMPSON, P. E., AND BOWEN, J. s. 1972. Interactions of differentiated primary sex factors in Chironomus tentans. Genetics, 70, 491-493.

ULlERICH, F. 1963. Geschlechtschromosomen und Geschlechtsbestimmung bei einigen Calliphorinen (Calliphoridae, Diptera). Chromosoma, 14, 45-110.

vajme, C. G., AND DUNBar, R. W. 1975. Chromosomal identification of eight species of the subgenus Edwardsellum near and including Simulium (Edwardsellum) damnosum Theobald (Diptera: Simuliiade). Tropenmed. Parasit., 26, 111-138. 
WALTER, L. 1973. Syntheseprozesse an den Riesenchromosomen von Glyptotendipes. Chromosoma, 41, 327-360.

WhrTE, M. J. D. 1978. Modes of speciation. Books in Biology Series, ed. C. I. Davern. Freeman and Co., San Francisco.

wülker, w., AND klötzli, A. M. 1973. Revision der Gattung Chironomus Meig. IV. Arten des lacunarius-(commutatus-) Komplexes. Arch. Hydrobiol., 72, 474-489.

WÜlKER, W. F., AND MARTIN, J. 1971. C. Karyosystematics of the Chironomus staegeri group. Stud. Nat. Sci. (Portales, N. M.), 1, (1), 22-34. 